Yuri Nakae MD, *

Michiaki Yamakage MD PhD, ${ }^{\dagger}$

Dai Horikawa MD, *

Mako Aimono MD, *

Keiko Tamiya MD PhD, *

Akiyoshi Namiki MD PhD ${ }^{\dagger}$

\title{
Triggering delay time and work of breathing in three paediatric patient- triggered ventilators
}

Purpose: To compare the effectiveness of three patient-triggered ventilators by evaluating triggering delay time and pressure-volume loops during initiation of inspiration.

Methods: In a two-part study, a model lung was used in part I and 20 children, after tracheal intubation, in part 2. Triggering delay time and work of breathing (WOB) during pressure support ventilation using three patient-triggered ventilators: Servo Ventilator $300^{\mathrm{TM}}$ VIP Bird ${ }^{\mathrm{TM}}$, and SLE 2000 Neonatal Ventilator ${ }^{\mathrm{TM}}$. Triggering delay time was from the beginning of negative deflection in the oesophageal pressure trace, to the onset of inspiration. The WOB was estimated directly by measuring the oesophageal pressure-volume loop.

Results: The Servo demonstrated superior triggering delay time and reduced WOB in the model study. The VIP Bird demonstrated shorter triggering delay and reduced WOB in the clinical component of the study. In the model lung, triggening delay time in the Servo $300[62 \pm 6 \mathrm{msec}$ (mean \pm SD)] was shorter than that in the VIP Bird (76 $\pm 7 \mathrm{msec}$ ) $(P<0.05$ ), and WOB with the SLE $2000(202 \pm 37 \mathrm{~g} \mathrm{~cm}$ ) was greater than with other ventilators, (Servo 300, 112 $\pm 32 \mathrm{~g} \cdot \mathrm{cm}$ and VIP Bird $72 \pm 41 \mathrm{~g} \cdot \mathrm{cm})(P<0.05)$. In the clinical study, triggering delay time in the VIP Bird $(52 \pm 19$ $\mathrm{msec}$ ) was shorter than in the other ventilators, Servo 300 (66 $\pm 14 \mathrm{msec})$, SLE $2000(68 \pm 65 \mathrm{msec})(P<0.05)$. The Servo $300(56 \pm 34 \mathrm{~g} \cdot \mathrm{cm})$ required higher WOB than the other ventilators: VIP Bird $(22 \pm 12 \mathrm{~g} \cdot \mathrm{cm})$, SLE 2000 $(14 \pm 3 \mathrm{gcm})(P<0.05)$.

Conclusion: Comparative model lung performance of these ventilators does not correspond with their clinical performance. In our clinical evaluation, the VIP Bird ventilator demonstrated superior performance with shorter triggering delay time, low WOB needed to initiate inspiration, and little air leak.

Objectif : Comparer l'efficacité de trois respirateurs déclenchés par le patient en évaluant le délai et les courbes pression-volume durant la phase initiale de l'inspiration.

Méthodes : Dans cette étude en 2 volets, un modèle pulmonaire a été utilisé pour la première partie et 20 enfants intubés pour la deuxième. On a étudié le délai de déclenchement de l'appareil et le travail respiratoire (TR) durant la ventilation selon le mode pression de support en utilisant trois respirateurs déclenchés par le patient: le ventilateur Servo $300 \otimes$, le Bird VIP $\circledast$ et le SLE 2000 Neonatal Ventilator $\AA$. Le délai de déclenchement de l'appareil a été calculé à partir du début de la défection négative sur le tracé de pression oesophagienne jusqu'au début de l'inspiration. Le TR a été estimé directement en mesurant la boucle pression-volume oesophagienne.

Résultats : Le Servo a démontré un meilleur délai de déclenchement et un TR réduit dans l'étude utilisant le modèle pulmonaire. Le Bird VIP a démontré un délai plus court et un TR diminué dans la partie clinique de l'étude. Dans le modèle pulmonaire, le délai de déclenchement du Servo 300 (62 $16 \mathrm{msec}$ (moyenne + écart type)) a été plus court que celui du Bird VIP $(76 \pm 7 \mathrm{msec})(P<0,05)$, et le TR avec le SLE $2000(202 \pm 37 \mathrm{~g} \cdot \mathrm{cm})$ a été plus grand qu'avec les deux autres ventilateurs (Servo 300, $112 \pm 32 \mathrm{~g} \cdot \mathrm{cm}$ et Bird VIP $72 \pm 41 \mathrm{~g} \cdot \mathrm{cm})(P<0,05)$. Dans la partie clinique de l'étude, le délai de déclenchement du Bird VIP $(52 \pm 19 \mathrm{msec})$ a été plus court qu'avec les autres ventilateurs. Servo $300(66 \pm 14 \mathrm{msec})$ et SLE $2000(68 \pm 65 \mathrm{msec})(P<0,05)$. Le TR du Servo $300(56 \pm 34 \mathrm{~g} \cdot \mathrm{cm})$ a été plus élevé que celui des deux autres ventilateurs : Bird VIP $(22 \pm 12 \mathrm{~g} \cdot \mathrm{cm})$ et SLE $2000(14 \pm 3 \mathrm{~g} \cdot \mathrm{cm})(P<0,05)$.

Conclusion : La performance de ces ventilateurs dans le modèle pulmonaire ne correspond pas à leur performance clinique. Au cours de notre évaluation clinique, le Bird VIP a démontré une performance supérieure aux autres avec un délai de déclenchement moindre, un faible TR pour initier l'inspiration et peu de fuites d'air.

From the Department of Anesthesia, Hokkaido Children's Medical Center, ${ }^{*}$ and the Department of Anesthesiology, Sapporo Medical University School of Medicine, ${ }^{\dagger}$ South 1, West 16, Chuo-ku, Sapporo, Hokkaido 060, Japan.

Address correspondence to: Yuri Nakac md, Department of Anesthesiology, Sapporo Medical University School of Medicine, South-1, West-16, Chuo-ku, Sapporo, Hokkaido 060, Japan; Phone: 81-11-611-2111 (Ext. 3568); Fax: 81-11-631-9683.

Accepted for publication December 18, 1997. 
$\mathrm{P}$ ATIENT-TRIGGERED ventilation provides several advantages including haemodynamic stability and prevention of barotrauma and intraventricular haemorrhage in infants. ${ }^{1-4}$ Pressure support ventilation augments spontaneous breathing and reduces work of breathing (WOB) during weaning from mechanical ventilation in children. ${ }^{5}$ However, it has been difficult for infants and small children to assist spontaneous breathing because of their rapid respiratory rates, potential leaks around a cuffless endotracheal tube, and high airway resistance imposed by a narrow endotracheal tube. Recently, several advanced ventilators, controlled by microprocessors and with devices to trigger spontaneous breathing, have appeared for paediatric use. ${ }^{6,7}$ Previous reports of these ventilators have evaluated the response time in rabbits and infants, ${ }^{8}$ the triggering delay time and WOB in a small model lung, ${ }^{9}$ and WOB and oxygen consumption in children. ${ }^{10}$

In this investigation, we have chosen to compare the effectiveness of each of the ventilators by using both a lung model and clinical performance with intubated and ventilated children. Measures we have chosen for comparison are triggering delay time and WOB as measured by negative deflection of oesophageal pressure during inspiration, while the ventilators are set on a form of pressure support mode.

\section{Materials and methods}

This is a two-part study, using a model lung in part I and 20 children whose tracheas were intubated in part II. The three advanced patient-triggered ventilators tested in this study were Servo Ventilator $300^{\mathrm{TM}}$ (Servo 300; Siemens Elema, Solna, Sweden), VIP Bird ${ }^{\mathrm{TM}}$ (VIP Bird; Bird, Palm Springs, CA), and SLE 2000 Neonatal Ventilator $^{\mathrm{TM}}$ (SLE 2000; SLE, Brighton, UK). The ventilators were respectively set to "pressure support" mode with the Servo 300 , to "volume-cycled synchronised intermittent mandatory ventilation (SIMV)/continuous positive airway pressure (CPAP)" mode with the VIP Bird, and to "patient-triggered ventilation (PTV)" mode with the SLE 2000. Pressure support and positive end-expiratory pressure (PEEP) levels were adjusted to 10 and $5 \mathrm{cmH}_{2} \mathrm{O}$ respectively in all three ventilators. Percent inspiratory rise time in the Servo 300, which defines the duration from the beginning of inspiration to the preset level of inspiratory flow, was set to minimise the WOB. Inspiratory time in the SLE 2000 was adjusted to $0.4 \mathrm{sec}$.

Airway pressure and flow rate were measured at the proximal end of the endotracheal tube using a differential pressure transducer (VarFlex ${ }^{\mathrm{TM}}$ flow transducer, Bicore, Irvine, $C A$ ) equipped with a pneumotachograph/pres- sure transducer system (CP-100; CP-100 Neonatal Pulmonary Monitor ${ }^{\mathrm{TM}}$, Bicore). The dead space of the flow transducer was $0.8 \mathrm{ml}$ and the resistance was 7.1 $\mathrm{cmH}_{2} \mathrm{O} \cdot \mathrm{L}^{-1} \cdot \mathrm{sec}^{-1}$. Intrapleural pressure was measured using an oesophageal catheter (SmartCath ${ }^{\mathrm{TM}}$, Bicore) which was also connected to the pulmonary function monitor. The oesophageal catheter had a balloon (length, $25 \mathrm{~mm}$, diameter, $6.5 \mathrm{~mm}$, when empty), sealed over a polyethylene catheter [Internal diameter (ID), $1.4 \mathrm{~mm}$, length, $28.5 \mathrm{~cm}$ ].

The triggering delay time was calculated as the time from the start of inspiration, determined as the time from the beginning of negative deflection in the oesophageal pressure trace, to the onset of inspiration of the ventilator. The negative deflection of oesophageal pressure during inspiration (Poes) was calculated as the difference between the end-expiratory oesophageal pressure and the lowest oesophageal pressure; the Poes value reflected the inspiratory WOB. ${ }^{11}$ The WOB was estimated directly by measuring the area enclosed between the oesophageal pressure-volume loop during inspiration and the relaxation curve of the chest wall, using the Campbell technique. ${ }^{12,13}$ Chest wall compliance was assumed to be $200 \mathrm{ml} \cdot \mathrm{cmH}_{2} \mathrm{O}^{-1}$. The mechanical WOB was expressed as work per litre of ventilation. Each ventilator was running for at least $30 \mathrm{~min}$ and the triggering delay time and WOB were expressed as the mean of the measurements over the last five minutes.

\section{Model lung study}

As previously reported, ${ }^{14}$ the model lung study consisted of one of the above ventilators, a two-bellowsin-a-box type model lung, ${ }^{15}$ and a pulmonary function monitor with two integral catheters. Briefly, the twobellows-in-a- box model lung consisted of two bellows placed in a two litre airtight plastic container. The upper bellows represented the lung, and the lower bellows represented the chest wall, including the diaphragm. The compliance of the lung and chest wall were adjusted to 6 and $20 \mathrm{ml} \cdot \mathrm{cmH}_{2} \mathrm{O}^{-1}$, respectively. The model lung was connected to each respiratory circuit of the ventilators with an endotracheal tube (ID; $3 \mathrm{~mm}$, length; $10 \mathrm{~cm}$ ). The oesophageal catheter was placed in the box of the model lung as the indication of intrapleural pressure. The model lung was set to the following parameters: tidal volume, $50 \mathrm{ml}$; respiratory rate, $40 \mathrm{~min}^{-1}$; and inspiratory to expiratory ratio, 1:2.

\section{Clinical study}

The clinical study was approved by the Hokkaido Children's Medical Center Committee on Human Research and informed consent was obtained from each patient's parent. Twenty ASA physical status I or II chil- 
dren (range 1 to $45 \mathrm{mo}$ ) were studied. They had undergone surgery and had entered the intensive care. Patients who had haemodynamic instability and/or primary pulmonary insufficiency were excluded from this study. All of the children were released from post-operative pain and were ready to begin the process of separation from mechanical ventilation.

The optimal size of endotracheal tube was chosen to allow a slight leak around the tube at $20 \mathrm{cmH}_{2} \mathrm{O}$ positive pressure. The oesophageal balloon for measuring intrapleural pressure was advanced the oesophagus until both the intraoesophageal pressure and airway pressure deflected negatively during inspiration made against an occluded airway. ${ }^{11}$ Percent leak was calculated as the difference between inspired and expired tidal volumes divided by inspired tidal volume. Inspiratory to expiratory ratio was calculated as time of inspiration divided by time of expiration. Dynamic compliance of the lung is defined as the change in volume divided by the change in transpulmonary pressure from the beginning to the end of inspiration. The transpulmonary pressure is determined as the difference between the airway pressure and the oesophageal pressure. The order of use of these ventilators was randomised in each patient.

All data are expressed as mean $\pm \mathrm{SD}$. The statistical significance of differences was determined using an analysis of variance. A value of $P<0.05$ was considered significant.

\section{Results}

\section{Model lung study}

The values of triggering delay time and WOB of the model lung are shown in Table I. All three ventilators tested showed short durations $<100 \mathrm{msec}$ for triggering inspiration in the model lung. The triggering delay in the Servo $300(62.2 \pm 6.2 \mathrm{msec})$ was shorter than that

TABLE I Triggering delay time and WOB in the-model lung study and clinical study

\begin{tabular}{|c|c|c|c|c|}
\hline & \multicolumn{2}{|c|}{$\begin{array}{c}\text { Model Lung Study } \\
\quad(n=5)\end{array}$} & \multicolumn{2}{|c|}{$\begin{array}{c}\text { Clinical Study } \\
(n=20)\end{array}$} \\
\hline & $\begin{array}{l}\text { Triggering } \\
\text { delay time } \\
\text { (msec) }\end{array}$ & $\begin{array}{l}W O B \\
(g \cdot \mathrm{cm})\end{array}$ & $\begin{array}{l}\text { Triggering } \\
\text { delay time } \\
\text { (msec) }\end{array}$ & $\begin{array}{l}W O B \\
(g \cdot c m)\end{array}$ \\
\hline Servo 300 & $62.2 \pm 6.2^{*}$ & $111.5 \pm 31.8$ & $65.7 \pm 13.9$ & $55.5 \pm 34.0^{\dagger}$ \\
\hline VIP Bird & $76.5 \pm 6.5$ & $72.3 \pm 40.5$ & $52.2 \pm 18.7 \dagger$ & $22.3 \pm 12.0$ \\
\hline SLE 2000 & $40.8 \pm 34.6$ & $202.0 \pm 37.2^{\dagger}$ & $67.6 \pm 64.8$ & $14.3 \pm 3.0$ \\
\hline
\end{tabular}

Variables shown are Mean $\pm \mathrm{SD}$. WOB: work of breathing. ${ }^{*} P<0.05$ vs the VIP Bird, ${ }^{\dagger} P<0.05$ vs the other two ventilators. The conditions of the model lung: tidal volume, $50 \mathrm{ml}$; respiratory rate, $40 \cdot \mathrm{min}^{-1}$; and inspiratory to expiratory ratio, $1: 2$. in the VIP Bird $(76.5 \pm 6.5 \mathrm{msec})(P<0.05)$. There was no difference in the triggering delay time between the SLE 2000 and the other two ventilators. The WOB of the model lung with the SLE $2000(202.0 \pm 37.2 \mathrm{~g} \cdot \mathrm{cm})$ was higher than that with the other two ventilators, the VIP Bird $(72.3 \pm 40.5 \mathrm{~g} \cdot \mathrm{cm})$ and the Servo 300 $(111.5 \pm 31.8 \mathrm{~g} \cdot \mathrm{cm})(P<0.05)$. There was no difference in the WOB between the Servo 300 and the VIP Bird.

\section{Clinical study}

The patients had received the following surgical operations: five neurosurgery, 10 cardiac surgery, and five abdominal surgery. The demographic characteristics of the children studied were as follows: age; $6.9 \pm 10.4$ mo, weight; $4.4 \pm 2.6 \mathrm{~kg}$, height; $50.0 \pm 6.1 \mathrm{~cm}$, and gestational age; $38.0 \pm 2.0 \mathrm{wk}$. The ID of the endotracheal tubes used was $3.4 \pm 0.5 \mathrm{~mm}$. The lung dynamic compliances of the patients were $0.87 \pm 0.35$ $\mathrm{ml} \cdot \mathrm{cmH}_{2} \mathrm{O}^{-1} \cdot \mathrm{kg}^{-1}$. The values of triggening delay time and WOB in the clinical study are shown in Table I. The triggering delay time with the VIP Bird $(52.2 \pm$ $18.7 \mathrm{msec}$ ) was shorter than that with the other two ventilators, the Servo $300(65.7 \pm 13.9 \mathrm{msec})$ and the SLE $2000(67.6 \pm 64.8 \mathrm{msec})(P<0.05)$. There was no difference in the triggering delay time between the Servo 300 and the SLE 2000. The WOB of the patients with the Servo $300(55.5 \pm 34.0 \mathrm{~g} \cdot \mathrm{cm})$ was greater than that with the other two ventilators, the VIP Bird (22.3 $\pm 12.0 \mathrm{~g} \cdot \mathrm{cm})$ and the SLE $2000(14.3 \pm 3.0 \mathrm{~g} \cdot \mathrm{cm})$ $(P<0.05)$. There was no difference in the WOB between the VIP Bird and SLE 2000. Compared with the mean value of WOB in the model lung study $(\sim 129$ $\mathrm{g} \cdot \mathrm{cm})$, the WOB of the patients in this clinical study $(\sim 31 \mathrm{~g} \cdot \mathrm{cm})$ was considerably lower $(P<0.01)$.

The variables measured with some respiratory conditions are shown in Table II. Respiratory rate and inspired tidal volume did not differ among the three groups. Percent leak was less in the VIP Bird (6.8 \pm $10.0 \%)$ than in the other two ventilators, the Servo $300(25.6 \pm 19.5 \%)$ and the SLE $2000(17.8 \pm 18.0 \%)$

TABLE II Variables measured in the clinical study

\begin{tabular}{|c|c|c|c|}
\hline & $\begin{array}{c}\text { Serpo } 300 \\
(n=20)\end{array}$ & $\begin{array}{l}\text { VIP Bird } \\
(n=20)\end{array}$ & $\begin{array}{c}S L E 2000 \\
(n=20)\end{array}$ \\
\hline Respiratory rate $\left(\min ^{-1}\right)$ & $32.9 \pm 17.3$ & $46.9 \pm 8.1$ & $51.0 \pm 22.3$ \\
\hline Inspired tidal volume (ml) & $36.3 \pm 12.1$ & $35.2 \pm 16.7$ & $29.0 \pm 29.5$ \\
\hline Percent leak (\%) & $25.6 \pm 19.5$ & $6.8 \pm 10.0^{\dagger}$ & $17.8 \pm 18.0$ \\
\hline $\begin{array}{l}\text { Inspiratory to } \\
\text { expiratory ratio }\end{array}$ & $0.39 \pm 0.17$ & $0.55 \pm 0.13^{\dagger}$ & $0.39 \pm 0.18$ \\
\hline
\end{tabular}

Variables shown are Mean $\pm S D$.

${ }^{t} P<0.05$ vs the other two ventilators. 
$(P<0.05)$. The inspiratory to expiratory ratio in the VIP Bird $(0.55 \pm 0.13)$ was higher than in the other two ventilators, the Servo $300(0.39 \pm 0.17)$ and the SLE $2000(0.39 \pm 0.18)(P<0.05)$.

\section{Discussion}

Although there were differences in the triggering delay times among the ventilators tested, we obtained an adequate delay time of $<100 \mathrm{msec}$ with all ventilators. The Servo 300 provides a constant expiratory bias flow (1.0 $\mathrm{L} \cdot \mathrm{min}^{-1}$ ) and triggers a change in the expiratory flow rate $\left(0.3\right.$ to $\left.1.0 \mathrm{~L} \cdot \mathrm{min}^{-1}\right)$ to initiate the inspiration. The VIP Bird uses a pneumotachometer (PARTNER ${ }^{\mathrm{TM}}$ ) at the proximal end of the endotracheal tube to sensitise the change in flow rate $\left(0.2\right.$ to $\left.0.5 \mathrm{~L} \cdot \mathrm{min}^{-1}\right)$. The SLE 2000 incorporates an airway pressure triggering device placed between the Y-piece and inspiratory circuit, which sensitises the changes in inspiratory airway pressure of over $0.5 \mathrm{cmH}_{2} \mathrm{O}$. This advanced technology could have contributed to the shortening of the triggering delay time. ${ }^{6-9}$

However, considerably higher.WOB was observed in the model lung than in the clinical study, even though there was little difference in the values of triggering delay time ibetween these studies (Table I). The discrepancy in the WOB could be explained by differences in experimental conditions. First, there was a small difference in the ID of the endotracheal tubes used in these studies. Because an endotracheal tube with $<5 \mathrm{~mm}$ of ID contributes to high airway resistance, leading to high $W O B,{ }^{16}$ the smaller endotracheal tube $(3.0 \mathrm{~mm}$ ID) used in the model lung study could have contributed to the higher WOB than in the clinical study ( $3.4 \pm 0.5 \mathrm{~mm}$ of ID). Second, the respiratory pattern could have contributed to the high WOB in the model lung study. The model lung passed into the expiratory phase earlier than did the ventilator, especially with the SLE 2000; and this would cause a higher WOB. Finally, the difference in the chest wall compliances between these studies could also have contributed to the discrepancy in the WOB. Although we used a chest wall compliance of $20 \mathrm{ml} \cdot \mathrm{cmH}_{2} \mathrm{O}^{-1}$ to calculate WOB in the model lung, the compliance of the children in the clinical study was not measured. Chest wall compliances are reported as $13 \mathrm{ml} \cdot \mathrm{cmH}_{2} \mathrm{O}^{-1}$ in full-term infants ${ }^{17}$ and $20 \mathrm{ml} \cdot \mathrm{cmH}_{2} \mathrm{O}^{-1}$ in children of $5 \mathrm{~kg}$ body weight. ${ }^{18}$ In addition, chest wall compliance is considered to be 200 $\mathrm{ml} \cdot \mathrm{cmH}_{2} \mathrm{O}^{-1}$ as a normal adult value used for calculating WOB in the CP-100. ${ }^{19}$ Therefore, WOB in the clinical study might have been larger if the chest wall compliance of the patients had directly been measured.

Among the three ventilators tested in the clinical study, the VIP Bird showed the best performance in the following respects: shorter triggering delay time, lower WOB, and little air leak (Tables I, II). The VIP Bird has a microstepper flow control valve, which is under control of internal microprocessors. Flow is regulated by this valve at the rate of $\sim 67 \mathrm{ml} \cdot \mathrm{min}^{-1}$ every $8 \mathrm{msec}$. This technology minimises flow overshoot, oscillations, and premature termination, resulting in a decrease of WOB. The VIP Bird also has a leak compensation system. Air leak around an endotracheal tube can cause the PEEP level to decrease below the preset or desired level. If the PEEP level decreases to the pressure support sensitivity level, autocycling will occur. The leak compensation of the VIP Bird can function when the airway pressure detected by the pneumotachometer decreases below the PEEP level of $0.25 \mathrm{cmH}_{2} \mathrm{O}$. Flow for leak compensation is introduced into the circuit to maintain the airway pressure within the preset baseline level of 0.25 $\mathrm{cmH}_{2} \mathrm{O}$. This feature allows synchronisation with the patient's breathing pattern, even with a minimum inspiratory effort. In contrast, the Servo 300 has no mechanism of maintaining the PEEP level. The increase of the air leak around the endotracheal tube prolongs the triggering delay time. The long triggering delay time disturbs synchronisation with the patient's own breathing, leading to the high WOB seen in the Servo 300 . Furthermore, in the Servo 300 the inspiratory phase passes into the expiratory phase if the flow decreases to $5 \%$ of peak flow during pressure support ventilation. Thus, this termination mechanism might be a factor in the increase of WOB. In the SLE 2000, the triggering device at the inspiratory circuit produces an inspiratory airway resistance of $20 \mathrm{cmH}_{2} \mathrm{O}$ through an airflow of $5 \mathrm{~L} \cdot \mathrm{min}^{-1}$. In addition, the SLE 2000 has a mechanism to produce PEEP and peak inspiratory pressure in the expiratory circuit. This mechanism often causes the end-expiratory phase to trigger and results in disturbance of synchronisation. The pneumotachograph in the VIP Bird per se has a small dead space $(<1 \mathrm{ml})$ and low airway resistance $\left(<1 \mathrm{cmH}_{2} \mathrm{O}\right.$ at $\left.6 \mathrm{~L} \cdot \mathrm{min}^{-1}\right)$. This unique design would also have contributed to the low WOB.

Our results in clinical use may be limited in comparing the performance of patient-triggered ventilators because the number of patients was small and the type of surgery was not standardised. Further investigation is required to confirm these results by increasing the number of patients and controlling the patients selected.

In conclusion, comparative model lung performance of these three patient-triggered ventilators does not correspond with their clinical performance. In our clinical evaluation, the VIP Bird ventilator demonstrated shorter triggering delay time than the other two ventilators tested, and median values for work of breathing needed 
to initiate inspiration, with little air leak. This improved performance may have been facilitated by the presence of a microstepper flow control valve and a leak compensation system characteristic of the VIP Bird system.

\section{References}

1 Greenough $A$, Wood S, Morley CJ, Davis JA. Pancuronuim prevents pneumothoraces in ventilated premature babies who actively expire against positive pressure inflation. Lancet 1984; 1: 1-3.

2 Rennie JM, South M, Morley CJ. Cerebral blood flow velocity variability in infants receiving assisted ventilation. Arch Dis Child 1987; 62: 1247-51.

3 Perlman JM, Goodman S, Kreusser KL, Volpe JJ. Reduction in intraventricular hemorrhage by elimination of fluctuating cerebral blood-flow velocity in preterm infants with respiratory distress syndrome. $\mathrm{N}$ Engl J Med 1985; 312: 1353-7.

4 Lipscomb AP, Thorburn RJ, Reynolds EOR, et al. Pneumothorax and cerebral haemorrhage in preterm infants. Lancet 1981; 1: 414-6.

5 Tokioka $H$, Kinjo $M$, Hirakawa $M$. The effectiveness of pressure support ventilation for mechanical ventilatory support in children. Anesthesiology 1993; 78: 880-4.

6 Mori N, Suzuki M. Trigger sensitivity of Servo 300 (Siemens Elema) for pressure support ventilation in an infant. Paediatr Anaesth 1994; 4: 27-34.

7 Greenough A, Hird MF, Chan V. Airway pressure triggered ventilation for preterm neonates. J Perinat Med 1991; 19: 471-6.

8 Bernstein G, Cleary JP, Heldt GP, Rosas JF, Schellenberg $L D$, Mannino FL. Response time and reliability of three neonatal patient-triggered ventilators. Am Rev Respir Dis 1993 ; 148: 358-64.

9 Nishimura $M$, Hess $D$, Kacmarek RM. The response of flow-triggered infant ventilators. Am I Respir Crit Care Med 1995; 152: 1901-9.

10 El-Khatib MF, Chatburn $R L$, Potts DL, Blumer $J$, Smith PG. Mechanical ventilators optimized for pediatric use decrease work of breathing and oxygen consumption during pressure-support ventilation. Crit Care Med 1994; 22: 1942-8.

11 Bebrakis PK, Baydur A, Jaeger MJ, Milic-Emili J. Lung mechanics in sitting and horizontal body positions. Chest $1983 ; 83$ : 643-6.

12 Campbell EJM. The pressure-volume diagram. In: Campbell EJM (Ed.). The Respiratory Muscles and the Mechanics of Breathing. London: Lloyd-Luke, 1958: 88-95.

13 Baydur A, Bebrakis PK, Zin WA, Jaeger $M$, Milic-Emili J. A simple method for assessing the validity of the esophageal balloon technique. Am Rev Respir Dis 1982; 126: 788-91.
14 Tamazaki $\Upsilon$, Yamakage $M$, Ujike $\Upsilon$, Namiki $A$. Changes in work of breathing during continuous positive airway pressure with increased airway resistance. Chest 1994; 105: 860-7.

15 Takahashi T, Takezawa J, Kimura T, Nishiwaki K, Shimada $\Upsilon$. Comparison of inspiratory work of breathing in T-piece breathing, PSV, and pleural pressure support ventilation (PSSV). Chest 1991; 100: 1030-4.

16 Shapiro M, Wilson $R K$, Casar $G$, Bloom $K$, Teague $R B$. Work of breathing through different sized endotracheal tubes. Crit Care Med 1986; 14: 1028-31.

17 Gerhardt $T$, Bancalari E. Chestwall compliance in fullterm and premature infants. Acta Paediatr Scand 1980; 69: 359-64.

18 Jacquez JA. Mechanics of ventilation and the work of breathing. In: Jacquez JA (Ed.). Respiratory Physiology. Washington: Hemisphere Publishing Corporation, 1979: 76-9.

19 Agostoni E, Mead J. Statics of the respiratory system. In: Fenn WO, Rahn $\mathrm{H}$ (Eds.). Handbook of Physiology Respiration. Washington: American Physiological Society, 1964: 387-409. 